\title{
Genetic Variants of the IL2 Gene Related to Risk and Survival in Patients With Colorectal Cancer
}

\author{
JAN DIMBERG $^{1 *}$, LEVAR SHAMOUN ${ }^{2,3^{*}}$, KALLE LANDERHOLM $^{4}$, \\ ROLAND E. ANDERSSON ${ }^{4}$, BLANKA KOLODZIEJ ${ }^{5}$ and DICK WÅGSÄTER ${ }^{3}$ \\ ${ }^{1}$ Department of Natural Science and Biomedicine, School of Health and Welfare, \\ Jönköping University, Jönköping, Sweden; \\ ${ }^{2}$ Department of Laboratory Medicine and Pathology, Region Jönköping County Hospital Ryhov, Jönköping, Sweden; \\ ${ }^{3}$ Department of Medical Cell Biology, Uppsala University, Uppsala, Sweden; \\ ${ }^{4}$ Department of Surgery, Jönköping, and Department of Clinical and Experimental Medicine, \\ Linköping University, Linköping, Sweden; \\ ${ }^{5}$ Department of Pathology, Region Jönköping County Hospital Ryhov, Jönköping, Sweden
}

\begin{abstract}
Background: Interleukin 2 (IL2) is a significant factor activating T-cell-mediated immune response by stimulation of natural killer cells, $T$-cells and in development of regulatory $T$ (Treg) cells. Recent studies have that IL2 participates in cancer development by modifying the local immune response. Based on the suggested role of the single nucleotide polymorphisms (SNPs) rs2069762, rs6822844 and rs11938795 of IL2 in the pathogenesis of certain diseases, the relationship of these SNPs with clinicopathological variables and their possible implication for prognosis and disease outcome were evaluated in a cohort of Swedish patients with colorectal cancer (CRC). Materials and Methods: TaqMan SNP genotype assays based on polymerase chain reaction were used for analysis of the IL2 SNPs in 467 patients with CRC and 467 healthy controls. Expression analysis of IL2 in plasma and CRC tissue was also performed. Results: The allelic variants $T$ in rs11938795 and $G$ in rs6822844 were significantly associated with a higher risk of CRC. Kaplan-Meier analysis showed that cancer-specific survival was worse for individuals with $C$ allele for rs2069762 with stage II CRC and with T allele for rs6822844 with stage III CRC. Conclusion: SNPs rs2069762, rs6822844 and rs11938795 of the IL2 gene may be helpful as prognostic biomarkers in the follow-up and management of the patients.
\end{abstract}

This article is freely accessible online.

*These Authors share first authorship.

Correspondence to: Dr. Jan Dimberg, Natural Science and Biomedicine, School of Health and Welfare, Jönköping University, Jönköping, Sweden. E-mail: jan.dimberg@ju.se

Key Words: SNP, colorectal cancer, immunoregulation, prognosis.
Colorectal cancer (CRC) is one of the most common types of malignancy worldwide (1). The pathogenesis of CRC is still not fully understood and the molecular mechanisms underlying tumor progression and metastasis are unclear. Cancer-related inflammation appears to be a hallmark of $\mathrm{CRC}$ and cytokines play a central role in the carcinogenic process since they are key regulators of immune responses $(2,3)$. Several interleukins (ILs) modulate intestinal tumor development, differentiation, and inflammatory and antiinflammatory responses. IL2 secreted by T-helper type 1 (Th1) cells is an important factor in activating T-cellmediated immune responses and stimulating the proliferation and differentiation of B-cells and natural killer cells. In addition, IL2 is involved in development of regulatory Tcells (Tregs) $(4,5)$.

Genetic variation, such as single nucleotide polymorphisms (SNPs), of inflammatory genes is suggested to play a role in the risk of CRC and survival of patients $(6,7)$. Polymorphic variants within the IL2/IL21 region at $4 \mathrm{q} 27$ have been discovered to be related to multiple diseases. The SNP rs6822844 is positioned in the IL2/IL21 intergenic region and is associated with multiple autoimmune diseases $(8,9)$. SNP rs11938795 is located in the same IL2/IL21 block and is related to Crohn's disease (10). Another SNP of the IL2 gene, rs2069762, is located in the promoter region and is implicated in increased susceptibility to gastric (11), oral (12), nasopharyngeal (13) and breast cancer (14).

A hot topic in CRC research is the search for clinically applicable biomarkers that can aid in diagnosis, prognostication and prediction of treatment response (15, 16). CRC staging is primarily based on the tumor-nodemetastasis (TNM) system of the American Joint Committee on Cancer (AJCC) classification system (17). Stage II CRC is generally considered as having a good prognosis, but a 
subgroup of patients (20-25\%) after surgery are at high risk for recurrence and should be considered as candidates for adjuvant chemotherapy. However, the identification of highrisk patients with stage II CRC remains difficult (18-20). These patients are identified on the basis of pathological and clinical parameters, including poorly differentiated tumor, lymphovascular or perineural invasion, perforation, T4 growth and fewer than 12 lymph nodes removed, but these are weak prognostic markers $(18,19,21)$.

Based on the suggested role of the SNPs rs2069762, rs6822844 and rs11938795 of IL2 in the pathogenesis of certain diseases, we evaluated the relationship of these SNPs with clinicopathological variables and their possible implication for prognosis and disease outcome in Swedish patients with CRC.

\section{Materials and Methods}

Patients and controls. A biobank of blood and tissue from patients with CRC has been collected at the Department of Surgery, Ryhov County Hospital, Jönköping, Sweden since 1996 and patient data has been prospectively recorded in a database. This study comprised blood samples from 467 patients (256 males and 211 females) with a mean age of 71 years (range $=25-94$ years) from this biobank who underwent surgical resection for primary colorectal adenocarcinoma between 1996 and 2016. Follow-up for the estimation of cancer-specific survival ended on the date of death or on January 31,2019 . Tumors were located in the colon in 247 and rectum in 220 and were classified according to AJCC (17: stage I in 79, stage II in 175, stage III in 147 and stage IV in 66). Other clinicopathological characteristics of the patients are shown in the Table I.

Healthy blood donors $(n=467)$ at Ryhov County Hospital, with no known CRC history, from the same geographical region as the patients were selected as the control population. This comprised 253 males and 214 females, with a mean age of 58 years (range $=33-68$ years). Blood samples from the patients were collected at the start of surgery and for the controls at the time of the blood donation. All blood samples were centrifuged to separate plasma and blood cells and then stored frozen at $-70^{\circ} \mathrm{C}$ until analysis.

The investigation was approved by the Regional Ethical Review Board in Linköping, Linköping, Sweden (Dnr.2013/271-31) and informed consent was obtained from each of the participants.

Genotyping of IL2 gene polymorphisms. DNA was isolated from all blood samples using QiaAmp DNA Blood Kit (Qiagen, Hilden, Germany). The TaqMan SNP genotype assays were used for analysis of the IL2 rs2069762 (ID C-15859930-10), rs6822844 (ID C-28983601-10) and rs11938795 (ID C-26012982-10) genotypes (Applied Biosystems, Foster City, CA, USA). Ten nanograms of DNA was mixed with TaqMan Genotyping Master Mix (Applied Biosystems) and was analyzed using a 7500 Fast Real-Time PCR System (Applied Biosystems). Amplification was performed using an initial cycle at $50^{\circ} \mathrm{C}$ for 2 min followed by one cycle at $95^{\circ} \mathrm{C}$ for $10 \mathrm{~min}$ and finally 40 cycles at $95^{\circ} \mathrm{C}$ for $15 \mathrm{~s}$ and at $60^{\circ} \mathrm{C}$ for $1 \mathrm{~min}$. The manual calling option in the allelic discrimination application ABI PRISM 7500 SDS software version 1.3.1 (Applied Biosystems) was then used to assign the genotypes.
Determination of IL2 concentration in plasma. Seventy-eight plasma samples were available from each group of the patients with CRC and healthy blood donors to measure IL2 level by commercial enzyme-linked immunosorbent assay (ELISA) kit (Abcam, Tokyo, Japan) according to the manufacturer's guidelines. The sensitivity of the assay was $2 \mathrm{pg} / \mathrm{ml}$. The group of patients comprised 38 males and 40 females, with a mean age of 72 years (range $=41-90$ years). The patients were classified with CRC stage I in 16, stage II in 26, stage III in 20 and stage IV in 16, and tumors were located in the colon in 49 and rectum in 29. Plasma was available for controls from 39 males and 39 females, with a mean age of 54 years (range $=41-68$ years).

Immunohistochemistry. Ten tumor samples were available for immunohistochemical staining to study the cell type origin of the IL2 expression. The samples were classified as stage I in three, stage II in two, stage III in two and stage IV in three. The selected formalinfixed, paraffin-embedded tissue specimens were cut into $3.5 \mu \mathrm{m}$ sections and were assessed on an automatic platform. Antigen retrieval was finished by heating for $52 \mathrm{~min}$ in Diva Decloaker, 10X (Biocare Medical, Concard, CA, USA) at $110^{\circ} \mathrm{C}$. Sections were treated with hydrogen peroxide for $5 \mathrm{~min}$ in order to block endogenous peroxidase which may disturb the interpretation of the color. Primary rabbit polyclonal antibody to IL2 (Abcam, Tokyo, Japan) was used at dilution of 1:100. The antibody was applied to the tissue sections which were incubated for $30 \mathrm{~min}$ at room temperature. MACH 4 universal HRP-Polymer Detection kit (Biocare Medical) was used and the reaction was visualized by Betazoid DAB Chromogen Kit (Biocare Medical). An experienced pathologist evaluated stained sections regarding location of IL2 expression

Statistical analysis. The differences in the frequencies of the IL2 gene polymorphisms between patients and the controls and according to clinical characteristics within the CRC subgroups were analyzed using the chi-squared test. The Hardy-Weinberg equilibrium was assessed for the genotypes. Survival analysis was performed by Kaplan-Meier analysis with log-rank test and Cox regression. The comparisons between groups regarding plasma levels of the $I L 2$ were performed with non-parametric tests. The Wilcoxon signed-rank test and the Mann-Whitney $U$-test were used for the analysis of the related and independent parameters. Statistical analysis was performed using Stata Statistical Software Release 15 (Stata Corp. College Station, TX, USA) and SPSS software for Windows, version 14.0 for (SPSS Inc., Chicago, IL, USA). Results were considered statistically significant at $p<0.05$.

\section{Results}

IL2 gene polymorphisms and CRC risk. No significant differences in the genotypic or in allelic frequencies were observed between the patients and the healthy control group for IL2 rs2069762 (Table II). When assessing the IL2 rs6822844 we noted a borderline significant $(p=0.061)$ and a significant $(p=0.018)$ difference between the patients and the healthy control group regarding the frequencies of the genotypes and alleles, respectively. The rate of GG genotype was $66.8 \%$ and that of GT/TT was $33.2 \%$ among patients, whilst being $60.2 \%$ and $39.8 \%$, respectively, in the healthy control group. The dominance of the GG genotype in patients 
Table I. Patient characteristics.

\begin{tabular}{llr}
\hline Characteristic & & \multicolumn{1}{c}{ Value } \\
\hline Age & Mean \pm SD & $71 \pm 11.2$ \\
Gender, n (\%) & Female & $211(45.2)$ \\
& Male & $256(54.8)$ \\
Tumour localization, n (\%) & Colon & $247(52.9)$ \\
& Rectum & $220(47.1)$ \\
Stage, n (\%) & I & $79(16.9)$ \\
& II & $175(37.5)$ \\
& III & $147(31.5)$ \\
Lymph nodes excised, n (\%) & IV & $66(14.1)$ \\
& $\geq 12$ & $207(44.9)$ \\
Tumor differentiation, n (\%) & Well & $254(55.1)$ \\
& Good & $52(11.1)$ \\
Cancer type, $\mathrm{n}(\%)$ & Poor & $308(66.0)$ \\
T-Stage, n (\%) & Mucinous & $107(22.9)$ \\
& T1 & $59(12.9)$ \\
& T2 & $13(2.8)$ \\
& T3 & $84(17.9)$ \\
N-Stage, n (\%) & T4 & $331(70.9)$ \\
M-Stage, n (\%) & N0 & $39(8.4)$ \\
Treatment, n (\%) & $\geq \mathrm{N} 1$ & $270(58.2)$ \\
\hline & M0 & $194(41.8)$ \\
& M1 & $400(86.0)$ \\
& Adjuvant & $65(14.0)$ \\
& & $127(27.5)$ \\
\hline
\end{tabular}

was significant $(p=0.035)$, with odds ratio (OR) of $1.33[95 \%$ confidence interval $(\mathrm{CI})=1.02-1.74]$. The prevalence of the $\mathrm{G}$ allele was $81.8 \%$ in patients and $77.4 \%$ in controls, corresponding to an increased risk of CRC, with OR of 1.31 (95\% CI=1.05-1.6; $p=0.018$ ). The distribution of IL2 rs11938795 genotypes also differed significantly $(p=0.027)$ between patients and controls. The TT genotype was overrepresented in patients with CRC $(58.2 \%)$ compared with controls $(51.8 \%)(p=0.048)$ (Table II). Consequently, the TT genotype was found to be associated with an increased risk of $\mathrm{CRC}$, with an OR of 1.30 (95\% CI=1.01-1.68). Additionally, the $\mathrm{T}$ allele was associated with increased risk of CRC, with an OR of 1.3 (95\% CI=1.07-1.61; $p=0.010)$.

Neither the patient nor the control group showed significant deviation from the Hardy-Weinberg equilibrium for any SNP (data not shown).

ClinicopathologicaI features and survival in relation to IL2 gene polymorphisms. There was no statistically significant difference in the referred genotypic distribution of IL2 gene polymorphisms in terms of various clinical characteristics (Tables III-V). With up to 23 years of follow-up, the KaplanMeier analysis showed that the cancer-specific survival curves differed between patients with AA and C-bearing genotypes for IL2 rs2069762 in those with stage II disease (Figure 1) and between GG and T-bearing genotypes for IL2 rs6822844 in
Table II. Genotypic and allelic frequencies of three single nucleotide polymorphisms (SNPs) of interleukin 2 gene in 467 patients with colorectal cancer and 467 healthy controls.

\begin{tabular}{llccc}
\hline SNP & & $\begin{array}{c}\text { Patients, } \\
(\mathrm{n}=467)\end{array}$ & $\begin{array}{c}\text { Controls, } \% \\
(\mathrm{n}=467)\end{array}$ & $p$-Value \\
\hline rs 2069762 & & & & \\
Genotype & AA & 51.4 & 54.0 & 0.442 \\
& AC & 40.5 & 36.6 & \\
Allele & CC & 8.1 & 9.4 & \\
& A & 71.6 & 72.3 & 0.791 \\
rs 6822844 & C & 28.4 & 27.7 & \\
Genotype & GG & 66.8 & 60.2 & 0.061 \\
& GT & 30.0 & 34.4 & \\
Allele & TT & 3.2 & 5.4 & \\
& G & 81.8 & 77.4 & 0.018 \\
rs 11938795 & T & 18.2 & 22.6 & \\
Genotype & TT & 58.2 & 51.8 & 0.027 \\
& TC & 36.2 & 38.6 & \\
Allele & CC & 5.6 & 9.6 & \\
& T & 76.3 & 71.1 & 0.010 \\
& C & 23.7 & 28.9 & \\
\hline
\end{tabular}

those with stage III disease (Figure 2). Carriers of the $\mathrm{C}$ allele for IL2 rs2069762 had an increased risk of death, with a hazard ratio of $2.90(95 \% \mathrm{CI}=1.19-7.07 ; p=0.014)$. Carriers of the $\mathrm{T}$ allele for IL2 rs6822844 also exhibited worse survival, with a hazard ratio of 1.85 (95\% $\mathrm{CI}=1.04-3.23$; $p=0.034$ ), whilst no significant differences in cancer-specific survival associated with IL2 rs11938795 were demonstrated.

Plasma level of IL2. The plasma IL2 was detectable in $44.8 \%(35 / 78)$ and $61.5 \%$ (48/78) of the patients and healthy blood donors, respectively. The IL2 plasma concentration was significantly $(p=0.030)$ lower in patients with CRC ( median $=0 \mathrm{pg} / \mathrm{ml}$, range $=0-528 \mathrm{pg} / \mathrm{ml}$ ) than in healthy blood donors $($ median $=3 \mathrm{pg} / \mathrm{ml}$, range $=0-386 \mathrm{pg} / \mathrm{ml})$. There were no associations between plasma IL2 level and clinical characteristics or IL2 SNP variants (data not shown).

Location of IL2 expression in CRC tissue. Predominantly heterogeneous cytoplasmic staining was evident, mainly in the epithelial compartment of cancer tissue. The immunoreactivity was also localized in stromal cells with morphological characteristics of leukocytes. Representative staining is shown in Figure 3.

\section{Discussion}

Several ILs are considered to affect intestinal tumor development and differentiation by modulating inflammatory and anti-inflammatory responses $(2,3)$. The SNPs of IL2, 


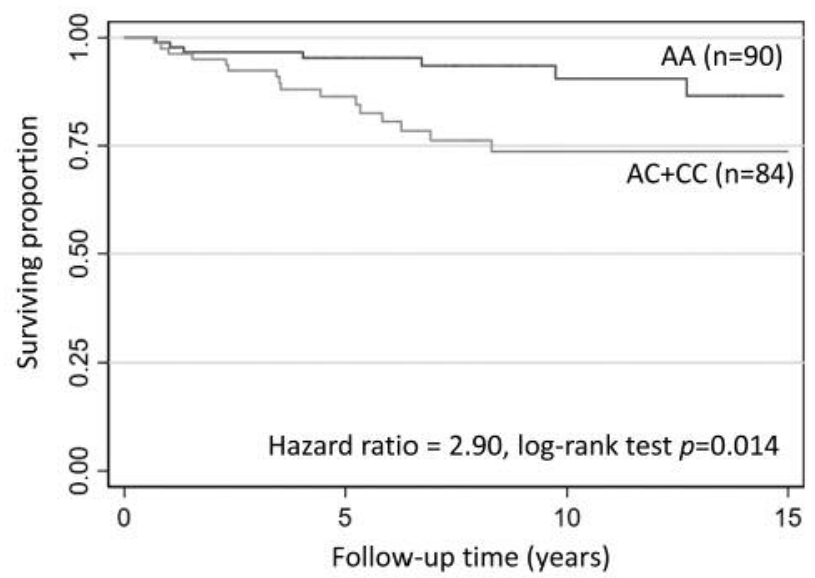

Figure 1. Kaplan-Meier plot comparing cancer-specific survival among patients with stage II colorectal cancer considering genotypes of rs2069762 single nucleotide polymorphism of interleukin 2 gene.

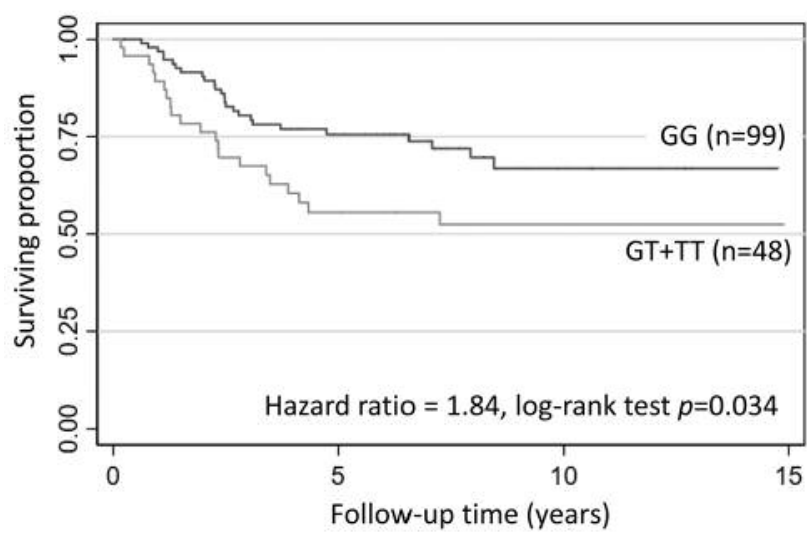

Figure 2. Kaplan-Meier plot comparing cancer-specific survival among patients with stage III considering genotypes of rs6822844 single nucleotide polymorphism of interleukin 2 gene.

Table III. Patient characteristics and association with the genotypic distribution of rs2069762 single nucleotide polymorphism of interleukin 2 gene.

\begin{tabular}{|c|c|c|c|c|}
\hline \multirow[b]{2}{*}{ Characteristic } & & \multicolumn{2}{|c|}{ Genotype } & \multirow[b]{2}{*}{$p$-Value } \\
\hline & & AA & $\mathrm{AC}+\mathrm{CC}$ & \\
\hline Total number & & 240 & 227 & \\
\hline Age, mean (SD) & $\mathrm{Mean} \pm \mathrm{SD}$ & $70.1 \pm 12.0$ & $71.4 \pm 10.3$ & 0.21 \\
\hline \multirow[t]{2}{*}{ Gender, n (\%) } & Female & $109(51.7)$ & $102(48.3)$ & 0.92 \\
\hline & Male & $131(51.2)$ & $125(48.8)$ & \\
\hline \multirow[t]{2}{*}{ Tumor localization, n (\%) } & Colon & $132(53.4)$ & $115(46.6)$ & 0.35 \\
\hline & Rectum & $108(49.1)$ & $112(50.9)$ & \\
\hline \multirow[t]{4}{*}{ Stage, n (\%) } & I & $34(14)$ & $45(20)$ & 0.40 \\
\hline & II & $91(38)$ & $84(37)$ & \\
\hline & III & $78(33)$ & $69(30)$ & \\
\hline & IV & $37(15)$ & $29(13)$ & \\
\hline Lymph nodes excised, n (\%) & $<12$ & $111 / 207(47)$ & $126 / 254(53)$ & 0.39 \\
\hline Tumor differentiation, $\mathrm{n}(\%)$ & Poor & $55 / 237(23)$ & $52 / 221(24)$ & 0.94 \\
\hline Cancer type cancer, n (\%) & Mucinous & $27 / 237(11)$ & $32 / 220(15)$ & 0.39 \\
\hline T-Stage, n $(\%)$ & $\mathrm{T} 4$ & $22 / 240(9)$ & $17 / 227(7)$ & 0.51 \\
\hline Treatment, n (\%) & Adjuvant & $66 / 236(28)$ & $61 / 225(27)$ & 0.84 \\
\hline
\end{tabular}

rs6822844 and rs11938795, are variants positioned in the IL2/IL21 intergenic regions and are connected within the KIAA1109/TENR/IL2/IL21 gene cluster block (10, 22). Previous studies have reported that $I L 2$ rs6822844 is associated with multiple autoimmune diseases $(8,9,23)$, ulcerative colitis (24) and Crohn's disease (10). The G allele being a risk factor is common to these diseases. A previous study showed that the TT genotype and T allele of IL2 rs11938795 were associated with an increased risk of Crohn's disease (10). In our study, we demonstrated that TT genotype and T allele of rs11938795 and $\mathrm{G}$ allele of rs6822844 were significantly associated with an increased risk of CRC.
Studies have shown that gene polymorphism of rs2069762, located in the promoter region of the IL2 gene, is implicated in increased susceptibility to cancer, including gastric (11), oral (12), nasopharyngeal (13) and breast cancer (14). We were not able to find this association with CRC risk, which is in line with a study by Bondurant et al. (7). On the other hand, we found that cancer-specific survival did differ between genotypes for rs2069762 and that carriers of the $\mathrm{C}$ allele had worse cancer-specific survival in those with stage II CRC. Moreover, we noted that the presence of $\mathrm{T}$ allele for IL2 rs6822844 was related to shorter survival in patients with stage III CRC. 


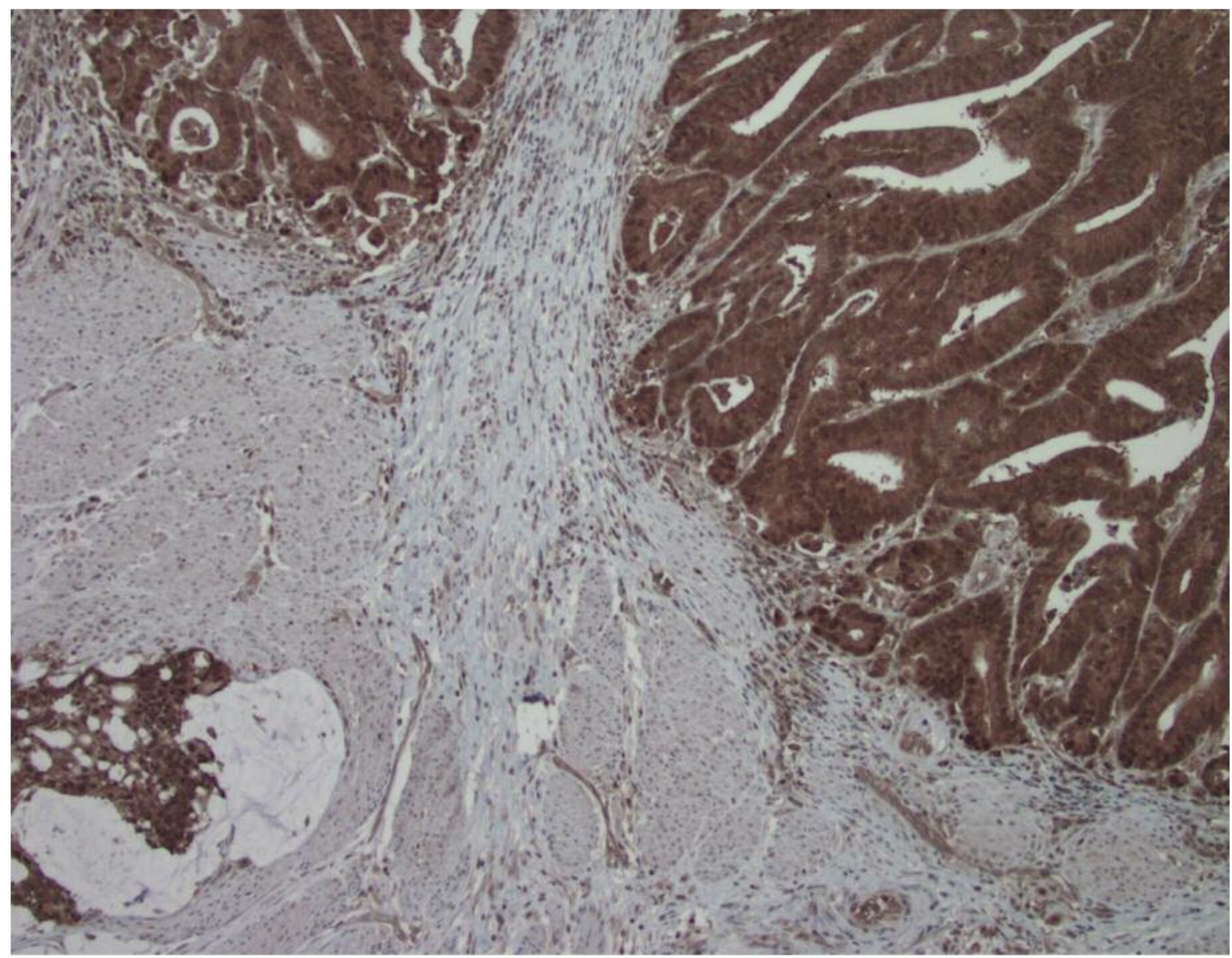

Figure 3. Expression of interleukin 2 protein in colorectal cancer tissue by immunohistochemical staining. Magnification, $\times 100$.

To our knowledge, the underlying mechanisms of IL2 gene polymorphisms involved in the risk of CRC are not clear. IL2 participates in the regulation of activities and proliferation of T- and natural killer cells $(4,5)$. Moreover, IL2 is assumed to play a crucial role in antitumor immunity and has potential as an immunotherapeutic agent against cancer, especially renal cancer, melanoma and CRC $(25,26)$. However, IL2 appears to have a dual effect in cancer immunotherapy, leading to poor outcomes in patients due to the dominant effect of immunosuppressive Treg cells in a therapeutic strategy with low-dose IL2 (25).

There are several factors influencing the outcome of CRC in clinical settings. The communication between CRC cells and their microenvironment, with stromal components, influences colorectal carcinogenesis (27). The genetic variation within genes encoding inflammatory mediators $(6$, 7) may have a modulatory role in colorectal carcinogenesis and affect the risk of developing CRC and survival. Due to different activated signaling cascades, the roles in later stages of cancer differ from those in early stages $(3,15,28-30)$.

Fichna et al. reported that IL2 rs6822844 G/T is associated with type 1 diabetes and that serum IL2 levels were lower in healthy controls carrying the GG genotype compared with controls with GT and TT genotypes (23). Moreover, Wei et al. showed that IL2 rs2069762 A/C contributes to nasopharyngeal carcinoma and that individuals carrying the AA genotype had higher serum IL2 levels (13). We did not detect any association between genotype and IL2 plasma concentration in patients with CRC or controls. However, we observed lower plasma IL2 levels in patients compared to healthy controls, which is in line with results from patients with nasopharyngeal carcinoma (13). In other available studies, the plasma levels of IL2 were elevated in patients with malignant melanoma (31) and lung cancer (32). Referring to these and our investigation, the findings indicate that there may be different mechanisms of immune regulation in different type of cancer. By using immunohistochemistry, we found the expression of IL2 to be localized mainly in the 
Table IV. Patient characteristics and association with the genotypic distribution of rs6822844 single nucleotide polymorphism of interleukin 2 gene.

\begin{tabular}{|c|c|c|c|c|}
\hline \multirow[b]{2}{*}{ Characteristic } & & \multicolumn{2}{|c|}{ Genotype } & \multirow[b]{2}{*}{$p$-Value } \\
\hline & & GG & $\mathrm{GT}+\mathrm{TT}$ & \\
\hline Total number & & 312 & 155 & \\
\hline Age & Mean \pm SD & $70.9(11.1)$ & $70.4(11.4)$ & 0.64 \\
\hline \multirow[t]{2}{*}{ Gender, n (\%) } & Female & $135(64.0)$ & $76(36.0)$ & 0.24 \\
\hline & Male & $177(69.1)$ & $79(30.9)$ & \\
\hline \multirow[t]{2}{*}{ Tumour localization, n (\%) } & Colon & $157(63.6)$ & $90(36.4)$ & 0.11 \\
\hline & Rectum & $155(70.5)$ & $65(29.5)$ & \\
\hline \multirow[t]{4}{*}{ Stage, $\mathrm{n}(\%)$} & I & $51(16)$ & $28(18)$ & 0.97 \\
\hline & II & $118(38)$ & $57(37)$ & \\
\hline & III & $99(32)$ & $48(31)$ & \\
\hline & IV & $44(14)$ & $22(14)$ & \\
\hline Lymph nodes excised, n (\%) & $<12$ & $138 / 310(45)$ & $69 / 151(46)$ & 0.81 \\
\hline Tumor differentiation, $\mathrm{n}(\%)$ & Poor & $75 / 306(25)$ & $32 / 152(21)$ & 0.41 \\
\hline Cancer type cancer, n (\%) & Mucinous & 42/307 (14) & $17 / 150(11)$ & 0.29 \\
\hline T-Stage, n (\%) & $\mathrm{T} 4$ & $27 / 312(9)$ & $12 / 155(8)$ & 0.74 \\
\hline Treatment, n (\%) & Adjuvant & $88 / 310(28)$ & $39 / 151(26)$ & 0.56 \\
\hline
\end{tabular}

Table V. Patient characteristics and the association with the genotypic distribution of rs11938795 single nucleotide polymorphism of interleukin 2 gene.

\begin{tabular}{|c|c|c|c|c|}
\hline \multirow[b]{2}{*}{ Characteristic } & & \multicolumn{2}{|c|}{ Genotype } & \multirow[b]{2}{*}{$p$-Value } \\
\hline & & $\mathrm{C} / \mathrm{C}+\mathrm{C} / \mathrm{T}$ & $\mathrm{T} / \mathrm{T}$ & \\
\hline Total number & & 195 & 272 & \\
\hline Age & Mean \pm SD & $70.0(11.8)$ & $71.2(10.7)$ & 0.27 \\
\hline \multirow[t]{2}{*}{ Gender, $\mathrm{n}(\%)$} & Female & $94(44.5)$ & $117(55.5)$ & 0.27 \\
\hline & Male & $101(39.5)$ & $155(60.5)$ & \\
\hline \multirow[t]{2}{*}{ Tumor localization, $\mathrm{n}(\%)$} & Colon & $106(42.9)$ & $141(57.1)$ & 0.59 \\
\hline & Rectum & $89(40.5)$ & $131(59.5)$ & \\
\hline \multirow[t]{4}{*}{ Stage, n (\%) } & I & $35(18)$ & $44(16)$ & 0.95 \\
\hline & II & $71(36)$ & $104(38)$ & \\
\hline & III & $62(32)$ & $85(31)$ & \\
\hline & IV & $27(14)$ & $39(14)$ & \\
\hline Lymph nodes excised, n (\%) & $<12$ & $84 / 191(44)$ & $123 / 270(46)$ & 0.74 \\
\hline Tumor differentiation, $\mathrm{n}(\%)$ & Poor & $42 / 191(22)$ & $65 / 267(24)$ & 0.56 \\
\hline Cancer type cancer, n (\%) & Mucinous & $21 / 189$ & $38 / 268(14)$ & 0.32 \\
\hline T-Stage, n (\%) & $\mathrm{T} 4$ & $17 / 195(9)$ & $22 / 272(8)$ & 0.81 \\
\hline Treatment, n (\%) & Adjuvant & $49 / 191(26)$ & $78 / 270(29)$ & 0.44 \\
\hline
\end{tabular}

cytoplasm of the cancer cells in all investigated cases. This suggests that IL2 may play a role in the development and progression of the tumor locally. The low plasma concentration of IL2 in patients with CRC may indicate that such patients have an impaired production of IL2 from leukocytes or restricted secretion of IL2 from CRC tissue.

Based on data from our cohort, rs2069762 and rs6822844 of IL2 may act as valuable biomarkers of clinical outcome of CRC in patients with stage II and III disease, respectively. One may speculate that these biomarkers reflect differences in the gene expression of IL2 and the immuno-antitumor effect. However, it is possible that the IL2 SNPs in our investigation play a latent role and are partially masked or diluted by other gene-gene or gene-environment/lifestyle interactions.

Because of the exploratory nature of our study, it must be considered a pilot study and further analysis with more cases are warranted to evaluate the significance of the findings. The strength of this study is a well-characterized patient cohort with prospectively collected tissue, blood samples and 
clinical data and with long follow-up time. Cases and controls were selected from only one hospital, which may not be representative of other populations. On the other hand, both populations came from a defined geographical region which may was representative of the general population in Sweden.

In conclusion, we identified subtypes of Swedish patients with CRC stage II and stage III based on IL2 rs2069762 and rs6822844. These biomarkers may be helpful in the followup and management of these patients. Moreover, we demonstrated that IL2 polymorphisms rs6822844 and rs11938795 were associated with an increased risk of developing CRC.

\section{Conflicts of Interest}

None.

\section{Authors' Contributions}

Conceived the study, participated in its design, analyzed data and prepared the manuscript: JD, LS and DW. Carried out the laboratory work: LS. Evaluated all pathological data: BK. Responsible for patient data and statistical analyzes: KL and REA. All Authors read and approved the final article.

\section{Acknowledgements}

This work was supported by grants from the Foundation of Clinical Cancer Research, Jönköping. The Authors thank Marita Skarstedt for the excellent technical support.

\section{References}

1 Siegel RL, Miller KD and Jemal A: Cancer statistics, 2018. CA Cancer J Clin 68: 7-30, 2018. PMID: 29313949. DOI: $10.3322 /$ caac. 21442

2 Klampfer L: Cytokines, inflammation and colon cancer. Curr Cancer Drug Targets 11: 451-464, 2011. PMID: 21247378.

3 Mager LK, Wasmer MH, Rau TT and Krebs P: Cytokineinduced modulation of colorectal cancer. Front Oncol, 2016. PMID: 27148488. DOI: 10.3389/fonc.20016.00096

4 Malek TR: The biology of interleukin-2. Annu Rev Immunol 26: 453-479, 2008. PMID: 18062768. DOI: 10.1146/annurev. immunol.26.021607.090357

5 Gaffen SL and Liu KD: Overview of interleukin - function, production and clinical applications. Cytokine 28: 109-123, 2004. PMID: 15473953. DOI: 10.1016/j.cyto.2004.06.010

6 Landi S, Gemignani F, Bottari F, Gioia-Patricola L, Guino E, Cambray M, Biondo S, Capella G, Boldrini L, Canzian F and Moreno V: Polymorphisms within inflammatory genes and colorectal cancer. J Negat Results Biomed 5: 15, 2006. PMID 17062130. DOI: $10.1186 / 1477-5751-5-15$

7 Bondurant KL, Lundgreen A, Herrick JS, Kadlubar S, Wolff RK and Slattery ML: Interleukin genes and associations with colon and rectal cancer risk and overall survival. Int J Cancer 132 : 905-915, 2013. PMID: 22674296. DOI: 10.1002/ijc. 27660
8 Maiti AK, Kim-Howard X, Viswanathan P, Guillen L, RojasVillarrage A, Deshmukh H, Direskeneli H, Saruhan-Direskeneli G, Canas C, Tobon GJ, Sawalha AH, Chernavsky AC, Anaya JM and Nath SK: Confirmation of an association between rs6822844 at the IL2-IL21 region and multiple autoimmune diseases. Arthritis Rheum 62: 323-329, 2010. PMID: 20112382. DOI: 10.1002/art.27222

9 Louahchi S, Allam I, Raaf N, Berkani L, Boucharef A, Abdessemed A, Khaldoun N, Bahaz N, Ladjouze-Rezig A, Nebbab A, Ghaffor M and Djidjik R: Association of rs6822844 within the KIAA1109/TENR/IL2/IL21 locus with rheumatoid arthritis in the Algerian population. HLA 87: 160-164, 2016. PMID: 26917059. DOI: $10.1111 / \tan .12757$

10 Marquez A, Orozco G, Martinez A, Palomino-Morales R, Fernandez-Arquero M, Mendoza JL, Taxonera C, Diaz-Rubio M, Gomez-Garcia M, Nieto A, Lopez-Nevot M. de la Concha EG, Martin J and Urcelay E: Novel association of the interleukin 2interleukin 21 region with inflammatory bowel disease. Am $\mathbf{J}$ Gastroenterol 104: 1968-1975, 2009. PMID: 19471255. DOI: 10.1038/ajg.2009.224

11 Wu J, Ding YB, Ke Q, Hu ZB, Yan ZH, Xue Y, Zhou Y, Hua ZL, Shu YQ, Liu P, Shen J, Xu YC and Shen HB: Promoter polymorphisms of IL2, IL4 and risk of gastric cancer in a highrisk Chinese population. Mol Carcinog 48: 626-632, 2009. PMID: 19058298. DOI: $10.1002 / \mathrm{mc} .20502$

12 Singh PK, Kumar V, Ahmad MK, Gupta R, Mahdi AA, Jain A, Bogra J and Chandra G: Association of -330 interleukin-2 gene polymorphism with oral cancer. Indian J Med Res 146: 730-737, 2017. PMID: 29664031. DOI: 10.4103/ijmr.IJMR_1949_15

13 Wei YS, Lan Y, Zhang L and Wang JC: Association of the interleukin-2 polymorphisms with interleukin-2 serum levels and risk of nasopharyngeal carcinoma. DNA Cell Biol 29: 363-368, 2010. PMID: 20438365. DOI: 10.1089/dna.2010.1019

$14 \mathrm{Hu}$ XB, Ouyang LZ and Tang LL: Interleukin-2 gene polymorphisms and prognosis of breast cancer. Genet Test Mol Biomarkers 17: 453-457, 2013. PMID: 23477313. DOI: 10.1089/ gtmb.2012.0494

15 Yiu AJ and Yiu CY: Biomarkers in colorectal cancer. Anticancer Res 36: 1093-1102, 2016. PMID: 26977004.

16 Sagaert X: Prognostic biomarkers in colorectal cancer: Where do we stand? Virchows Arch 464: 379-391, 2014. PMID: 24487787. DOI: $10.1007 / \mathrm{s} 00428-013-1532-\mathrm{z}$

17 Amin MB, Greene FL, Edge SB, Compton CC, Gershenwald JE, Brookland RK, Meyer L, Gress DM, Byrd DR and Winchester DP: The Eighth Edition AJCC Cancer Staging Manual: Continuing to build a bridge from a population-based to a more "personalized" approach to cancer staging. CA Cancer J Clin 67: 93-99, 2017. PMID: 28094848. DOI: 10.3322/caac. 21388

18 Akiyoshi T, Kobunai $\mathrm{T}$ and Watanabe T: Recent approaches to identifying biomarkers for high-risk stage II colon cancer. Surg Today 42: 1037-1045, 2012. PMID: 22961195. DOI: 10.1007/ s00595-012-0324-4

19 Bockelman C, Engelmann, Kaprio T, Hansen TF and Glimelius B: Risk of recurrence in patients with colon cancer stage II and III: A systematic review and meta-analysis of recent literature. Acta Oncol 54: 5-16, 2015. PMID: 25430983. DOI: 10.3109/ 0284186X.2014.975839

20 Fang SH, Efron JE, Berho ME and Wexner SD: Dilemma of stage II colon cancer and decision making for adjuvant 
chemotherapy. J Am Coll Surg 219: 1056-1069, 2014. PMID: 2544002. DOI: 10.1016/j.jamcollsurg.2014.09.010

21 Stocchi L, Fazio VW, Lavery I and Hammel J: Individual surgeon, pathologist and other factors affecting lymph node harvest in stage II colon carcinoma. Is a minimum of 12 examined lymph nodes sufficient? Ann Surg Oncol 18: 405-412, 2011. PMID: 20839064. DOI: 10.1245/s10434-010-1308-5

22 Hollis-Moffatt JE, Chen-Xu M, Topless R, Dalbeth N, Gow PJ, Harrison AA, Highton J, Jones PBB, Nissen M, Smith MD, van Rij A, Jones GT Stampe LK and Merriman TR: Only one independent genetic association with rheumatoid arthritis within the KIAA1109-TENR-IL2-IL21 locus in Caucasian sample sets: confirmation of association of rs6822844 with rheumatoid arthritis at a genome-wide level of significance. Arthritis Res Ther 12: R116, 2010. PMID: 20553587. DOI:10.1186/ar3053

23 Fichna M, Zurawek M, Fichna P, Ziolkowska-Suchanek I, Januszkiewicz D and Nowak J: Polymorphic variant at the IL2 region is associated with type 1 diabetes and may affect serum levels of interlekin-2. Mol Biol Rep 40: 6957-6963, 2013. PMID: 24154763. DOI: 10.1007/s11033-013-2815-9

24 Festen EAM, Goyette P, Scott R, Annese V, Zhernakova A, Lian J, Lefebvre C, Brant SR, Cho JH, Silverberg MS, Taylor KD, De Jong DJ, Stokkers PC, McGovern D, Palmieri O, Achkar JP, Xavier RJ, Daly M, Duerr RH, Wijmenga C, Weersma RK and Rioux JD: Genetic variants in the region harbouring IL2/IL21 associated to ulcerative colitis. Gut 58: 799-804, 2008. PMID: 19201773. DOI: $10.1136 /$ gut.2008.166918

25 Choudhry H, Helmi N, Abdulaal WH, Zeyadi M, Zamzami MA, Wu W, Mahmoud MM, Warsi MK, Rasool M and Jamal MS: Prospects of IL2 in cancer immunotherapy. Biomed Res Int 2018: 9056173, 2018. PMID: 29854806. DOI 10.1155/2018/ 9056173

26 Roviello G, Zanotti L, Correale P, Gobbi A, Wigfield S, Guglielmi A, Pacifico C and Generali D: Is still there a role for IL2 for solid tumors other than melanoma or renal cancer? Immunotherapy 9: 25-32, 2017. PMID: 28000528. DOI: 10. 2217/imt/2016-0107
27 Quail DF and Joyce JA: Microenvironmental regulation of tumor progression and metastasis. Nat Med 19: 1423-1437, 2013. PMID: 242022395. DOI: $10.1038 / \mathrm{nm} .3394$

28 Al-Sohaily S, Biankin A, Leong R, Kohonen-Corish M and Warusavitarne J: Molecular pathways in colorectal cancer. J Gastroenterol Hepatol 27: 1423-1431, 2012. PMID: 22694276. DOI: $10.1111 / \mathrm{j} .1440-1746.2012 .07200 . \mathrm{x}$

$29 \mathrm{Li}$ FY and Lai MD: Colorectal cancer, one entity or three. J Zhejiang Univ Sci B 10: 219-229, 2009. PMID: 19283877. DOI: 10.1631/jzus.b0820273

30 Pandurangan AK, Divya T, Kumar K, Dineshbabu V, Velavan B and Sudhandiran G: Colorectal carcinogenesis: Insights into the cell death and signal transduction pathways: A review. World J Gastrointest Oncol 10: 244-259, 2018. PMID: 30254720. DOI: 10.4251/wjgo.v10.19.244

31 Kucera R, Topolcan O, Treskova I, Kinkorova J, Winddrichova J, Fuchsova R, Svobodova S, Treska V, Babuska V, Novak J and Smejkal J: Evaluation of IL2, IL-6, IL-8 and IL-10 in malignant melanoma diagnostics. Anticancer Res 35: 3537-3542, 2015. PMID: 26026122.

32 Orditura M, Romano C, De Vita F, Galizia G, Lieto E, Infusino S, De Cataldis G, and Catalano G: Behaviour of interleukin-2 serum levels in advanced non-small-cell lung cancer patients: relationship with response to therapy and survival. Cancer Immunol Immunother 49: 530-536, 2000. PMID: 11129323. 